
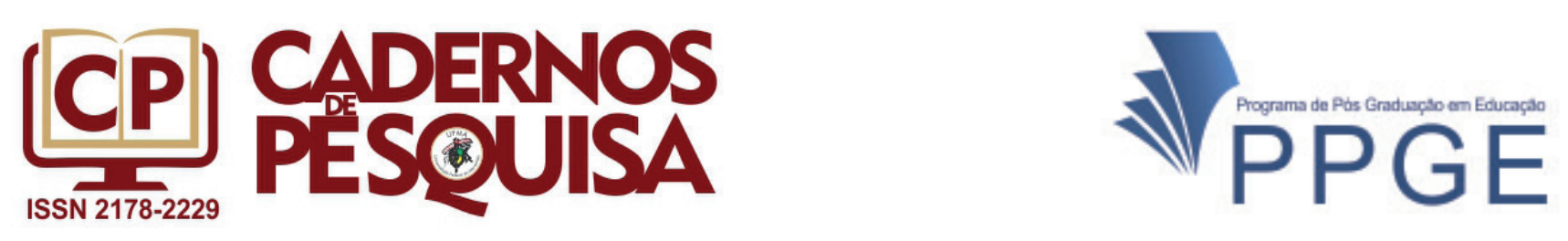

\title{
DE LEITOR A ESCRITOR: JOÃO UBALDO RIBEIRO E A SUA FORMAÇÃO EM "UM BRASILEIRO EM BERLIM"
}

\author{
FROM READER TO WRITER: JOÃO UBALDO RIBEIRO AND \\ HIS TRAINING IN “UM BRASILEIRO EM BERLIM”
}
DE LECTOR A ESCRITOR: JOÃO UBALDO RIBEIRO Y SU FORMACIÓN EN “UM BRASILEIRO EM BERLIM"

\author{
Katiene Nogueira da Silva \\ ORCID: https://orcid.org/0000-0002-1280-3041
}

Roni Cleber Dias de Menezes

ORCID: http://orcid.org/0000-0001-8661-1328

\begin{abstract}
Resumo: O artigo explora a dimensão formativa de João Ubaldo Ribeiro através do relato autobiográfico acerca de sua infância e sua relação com a leitura no livro Um brasileiro em Berlim, publicado em 1995 em língua portuguesa e que narra peripécias saborosas de uma estada na capital da Alemanha no início dos anos 1990, convidado por um programa de intercâmbio alemão para realizar um roteiro literário pelo país. O início da nossa relação com os livros pode marcar o desenvolvimento do gosto pela leitura e a constituição do hábito de ler, entendendo o mesmo como a criação da necessidade de realizar tal atividade para a obtenção de algum tipo de satisfação, como buscar conhecimento, ocupar o tempo livre ou simplesmente para sentir prazer. Neste livro, a sua história com os livros tem em seu pai e sua avó personagens importantes que lhe despertaram o fascínio por tal prática: para quem, quando pequeno, "a leitura era uma brincadeira como outra qualquer, embora certamente a melhor de todas". Esse capital cultural representado pelas gerações que o precederam teria, nas palavras do autor, cumprido um papel decisivo tanto na sua formação estética quanto na percepção aí adquirida de pertença a um universo mais amplo de leitores. Ao publicar as crônicas escritas no período em que viveu em Berlim, Ubaldo evidencia como a sua relação com os livros proliferou e o transformou em um dos principais escritores da literatura brasileira contemporânea.
\end{abstract}

Palavras-chave: autobiografia; formação do leitor; literatura brasileira; educação

\begin{abstract}
The article explores the formative dimension of João Ubaldo Ribeiro through the autobiographical account of his childhood and his relationship with reading in the book Um Brasileiro em Berlim, published in 1995 in Portuguese and which narrates tasty adventures of a stay in the capital of Germany in early 1990's, invited by a German exchange program to conduct a literary tour across the country. The beginning of our relationship with books can mark the development of a taste for reading and the constitution of the habit of reading, understanding the same as the creation of the need to carry out such an activity to obtain some kind of satisfaction, such as seeking knowledge, occupying free time or simply to feel pleasure. In this book, his story with books has important characters in his father and grandmother who aroused his fascination for this
\end{abstract}


practice: for those who, when he was little, "reading was a game like any other, although certainly the best of all". This cultural capital represented by the generations that preceded it would, in the author's words, have played a decisive role both in its aesthetic formation and in the perception acquired there of belonging to a wider universe of readers. By publishing the chronicles written during the period in which he lived in Berlin, Ubaldo shows how his relationship with books has proliferated and transformed him into one of the main writers of contemporary Brazilian literature.

Keywords: autobiography; reader training; Brazilian literature; education

Resumen: El artículo explora la dimensión formativa de João Ubaldo Ribeiro a través del relato autobiográfico de su infancia y su relación con la lectura en el libro Um Brasileiro em Berlim, publicado en 1995 en portugués y que narra sabrosas aventuras de una estancia en la capital de Alemania a principios de 1990, invitado por un programa de intercambio alemán para realizar una gira literaria por todo el país. El inicio de nuestra relación con los libros puede marcar el desarrollo del gusto por la lectura y la constitución del hábito de leer, entendiendo lo mismo que la creación de la necesidad de realizar dicha actividad para obtener algún tipo de satisfacción, como buscar conocimiento, ocupar el tiempo libre o simplemente para sentir placer. En este libro, su historia con libros cuenta con personajes importantes en su padre y abuela que despertaron su fascinación por esta práctica: para quienes, cuando era pequeño, "leer era un juego como cualquier otro, aunque sin duda el mejor de todos". Este capital cultural representado por las generaciones que le precedieron habría jugado, en palabras del autor, un papel decisivo tanto en su formación estética como en la percepción allí adquirida de pertenencia a un universo más amplio de lectores. Al publicar las crónicas escritas durante el período en el que vivió en Berlín, Ubaldo muestra cómo su relación con los libros ha proliferado y lo ha convertido en uno de los principales escritores de la literatura brasileña contemporánea.

Palabras clave: autobiografía; formación de lectores; Literatura brasileña; educación

\section{INTRODUÇÃO}

O livro "Um brasileiro em Berlim" resulta da reunião de diversas crônicas produzidas por João Ubaldo Ribeiro quando de sua estada de 15 meses na capital alemã, iniciada em abril de 1990 - portanto, pouco tempo depois da queda do Muro e simultânea à reunificação do país - a convite da DAAD (Deutscher Akademische Austauschdienst ${ }^{1}$ ) para aí realizar um roteiro literário. Nesse período, manteve colaboração com alguns veículos de comunicação do país, dentre os quais se destacam as crônicas produzidas regularmente para o Frankfurter Rundschau². A publicação vem à estampa alguns anos depois do retorno ao Brasil, primeiramente na língua alemã, pela Editora Suhrkamp, de Frankfurt, em 1994, com o título Ein Brasilianer in Berlin, correspondente, pois, ao assumido pela versão em português, vinda à lume no ano seguinte pela Editora Nova Fronteira.

Composto por 16 crônicas, sendo 15 relativas ao período vivido em Berlim, a publicação, a título de dar vazão textual a histórias saídas da experiência concreta e da imagi-

1 Entidade alemã, da área de intercâmbio acadêmico, que convida artistas, escritores e intelectuais, oferecendo para isso bolsas, para passar temporadas em Berlim. A esse respeito, confira: Um brasileiro em Berlim - Posfácio - Procurando o brasileiro em Berlim: João Ubaldo Ribeiro na Alemanha, por Ray-Güde Mertin.

2 Jornal de circulação diária fundado na cidade de Frankfurt em $1^{\circ}$ de agosto de 1945 e que se mantém ativo até os dias atuais. 
nação de João Ubaldo Ribeiro, oferece ao leitor muitas entradas para intuir a propósito dos processos de produção escriturária em literatura e, o que nos propomos desenvolver aqui, o desenvolvimento do gosto pela leitura, observados a partir dos nexos entre contributos familiares e escolares na formação do leitor.

\section{JOÃO UBALDO RIBEIRO E A DESCOBERTA DO BRASILEIRO}

Figura 1: João Ubaldo Ribeiro

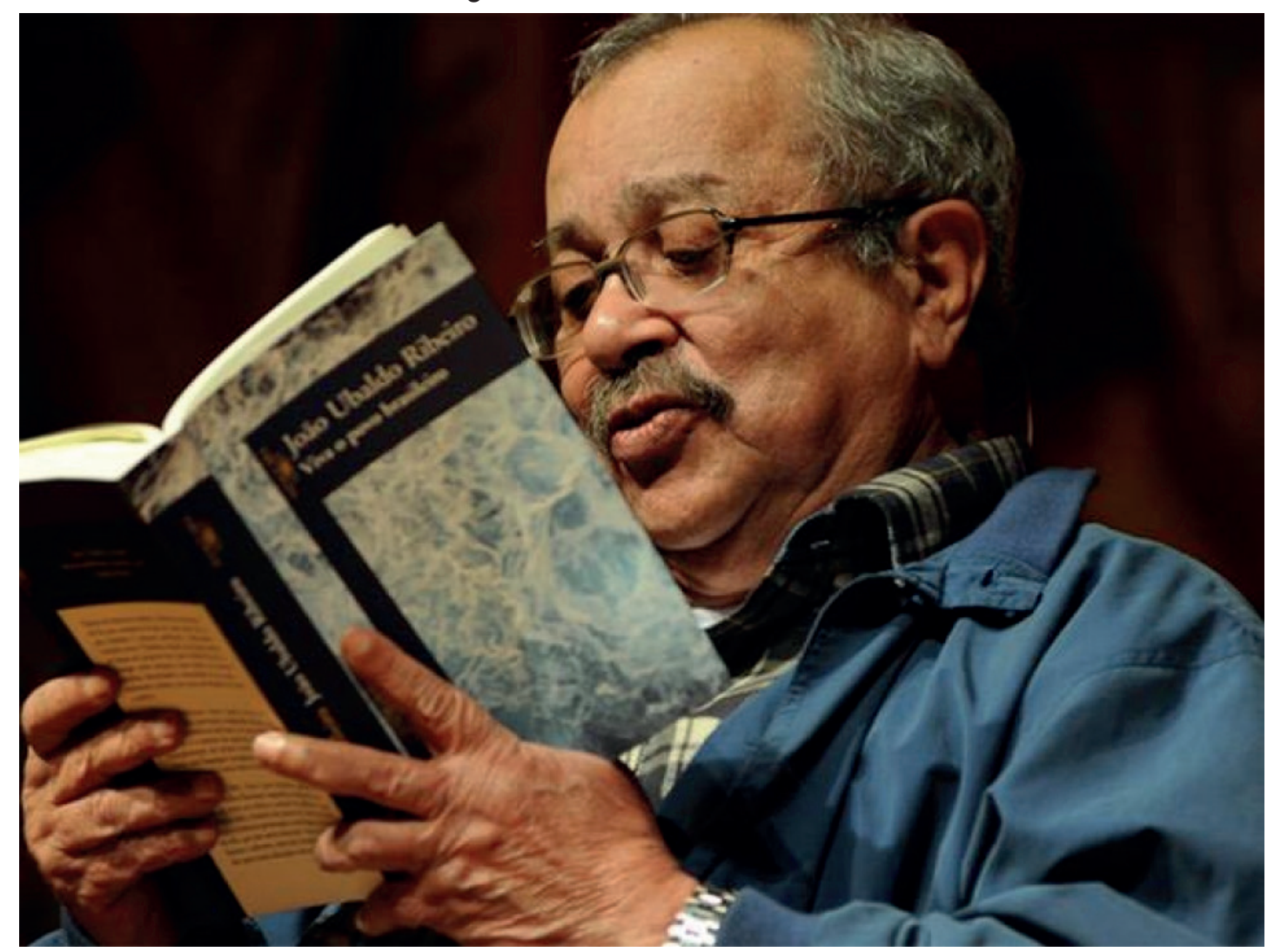

Fonte: João Ubaldo Ribeiro: "Viva o povo brasileiro" - Revista Prosa Verso e Arte

João Ubaldo (Osório Pimentel) Ribeiro, romancista, contista, cronista, roteirista e jornalista, nasceu em Itaparica (BA), em 23 de janeiro de 1941. Viveu com sua família em Sergipe, dos primeiros meses de idade até cerca de onze anos, onde o pai era professor e político. Viveu um ano em Lisboa e um ano no Rio de Janeiro para, em seguida, fixar-se em Itaparica, onde viveu aproximadamente sete anos. Estudou na Universidade Federal da Bahia, onde formou-se bacharel em Direito (1959-62), contudo, jamais chegou a advogar. Cursou pós-graduação em Administração Pública pela mesma Universidade e mestrado (Master of Science) em Administração Pública e Ciência Política pela Universidade do Sul da Califórnia, com bolsa de estudos fornecida pela embaixada norte-americana no Brasil. Ubaldo foi professor da Escola de Administração e da Faculdade de Filosofia da Universidade Federal da Bahia e professor da Escola de Administração da Universidade Católica de 
Salvador. Iniciou sua carreira de jornalista como repórter no Jornal da Bahia em 1957, tendo aí também desempenhado posteriormente funções de redator, chefe de reportagem e colunista; na Tribuna da Bahia atuou como colunista, editorialista e editor-chefe. Foi colunista do jornal Frankfurter Rundschau, na Alemanha; colaborador de diversos jornais e revistas no país e no exterior, entre os quais, além dos citados, Diet Zeit (Alemanha), The Times Literary Supplement (Inglaterra), O Jornal (Portugal), Jornal de Letras (Portugal), Folha de S. Paulo, O Globo, O Estado de S. Paulo, A Tarde e muitos outros. Sua formação literária foi iniciada ainda nos primeiros anos de estudante. Foi um dos jovens escritores brasileiros que participaram do International Writing Program da Universidade de lowa. Trabalhando na imprensa, pôde também escrever seus livros de ficção e construir uma carreira que o consagrou como cronista, romancista, jornalista e tradutor. Seus primeiros trabalhos literários foram publicados em diversas coletâneas (Reunião, Panorama do Conto Baiano). Aos 21 anos de idade, escreveu seu primeiro livro, Setembro não Tem Sentido, que ele desejava intitular como A Semana da Pátria, contra a opinião do editor. O segundo foi Sargento Getúlio, de 1971. Em 1974, publicou Vencecavalo e o Outro Povo, que por sua vontade se chamaria A Guerra dos Paranaguás. Entre 1990 e 1991, morou em Berlim, a convite do Instituto Alemão de Intercâmbio (DAAD - Deutscher Akademischer Austauschdienst). Na volta, passou a morar no Rio de Janeiro. Do casamento com Berenice de Carvalho Batella Ribeiro teve dois filhos. Do casamento anterior com Mônica Maria Roters, João Ubaldo teve duas filhas.

O livro Sargento Getúlio foi consagrado foi como um marco do moderno romance brasileiro e filiou o autor, segundo a crítica, a uma vertente literária que sintetiza o melhor de Graciliano Ramos e o melhor de Guimarães Rosa. A história, ambientada na década de 1950, apresenta elementos da cultura e dos costumes do Nordeste brasileiro e, em particular, dos sergipanos, numa linguagem amparada em grande parte "sobre neologismos, reproduções dos desvios da norma culta e frases entrecortadas, na qual a violência do meio e a precariedade psicológica dos próprios personagens são retratadas com intensidade" (ENCICLOPÉDIA Itaú Cultural de Arte e Cultura Brasileira, 2021, verbete João Ubaldo Ribeiro). Esse regionalismo extremamente rico e fiel dificultou a versão do romance para o inglês, obrigando o próprio autor a fazer esse trabalho. A seu respeito pronunciaram-se, nos Estados Unidos e na França, as colunas literárias de todos os grandes jornais e revistas. Em 1999, foi um dos escritores escolhidos em todo o mundo para dar depoimento, ao jornal francês Libération, sobre o Terceiro Milênio. E Viva o Povo Brasileiro foi o tema do exame de Agrégation, concurso para detentores de diploma de graduação na universidade francesa. Este romance e Sargento Getúlio constaram da maior parte das listas dos cem melhores romances brasileiros do século XX. Ubaldo foi o sétimo ocupante da Cadeira $\mathrm{n}^{\circ}$ 34 da Academia Brasileira de Letras, eleito em 7 de outubro de 1993, na sucessão de Carlos Castello Branco e recebido em 8 de junho de 1994 pelo acadêmico Eduardo Portella. Faleceu no dia 18 de julho de 2014, no Rio de Janeiro, aos 73 anos. 
Dentre suas obras, inclui-se:

Setembro não tem sentido. Rio de Janeiro: José Álvaro Editor, 1968.

Sargento Getúlio. Rio de Janeiro: Artenova, 1971.

Vencecavalo e o Outro Povo. São Paulo: Artenova, 1974.

Vila Real. Rio de Janeiro: Nova Fronteira, 1979.

Política: quem manda, por que manda, como manda. Rio de Janeiro: Nova Fronteira, 1981.

Viva o povo brasileiro. Rio de Janeiro: Nova Fronteira, 1984.

Sempre aos domingos. Rio de Janeiro: Nova Fronteira, 1988.

O sorriso do lagarto. Rio de Janeiro: Nova Fronteira, 1989.

O feitiço da llha do Pavão. Rio de Janeiro: Nova Fronteira, 1997.

A casa dos budas ditosos. Rio de Janeiro: Editora Objetiva, 1999.

Arte e ciência de roubar galinhas. Rio de Janeiro: Nova Fronteira, 1999.

Miséria e grandeza do amor de Benedita. Rio de Janeiro: Ed. Nova Fronteira, 2000.

O conselheiro Come. Rio de Janeiro: Ed. Nova Fronteira, 2000.

Diário do farol. Rio de Janeiro: Ed. Nova Fronteira, 2002.

A gente se acostuma a tudo. Rio de Janeiro: Ed. Nova Fronteira, 2006.

O rei da noite. Rio de Janeiro: Ed. Objetiva, 2008.

O albatroz azul. Rio de Janeiro: Ed. Nova Fronteira, 2009.

Contos e crônicas para ler na escola. Rio de Janeiro: Ed.: Objetiva, 2010.

O escritor recebeu muitos prêmios e distinções ao longo da carreira, entre eles estão:

- Prêmio Golfinho de Ouro, do Estado do Rio de Janeiro, conferido, em 1971, pelo romance Sargento Getúlio;

- Dois prêmios Jabuti, da Câmara Brasileira do Livro, em 1972 e 1984, respectivamente para o Melhor Autor e Melhor Romance do Ano, pelo romances Sargento Getúlio e Viva o povo brasileiro;

_ Prêmio Altamente Recomendável - Fundação Nacional do Livro Infantil e Juvenil,1983, para Vida e Paixão de Pandonar, o Cruel ;

- Prêmio Anna Seghers, em 1996 (Mogúncia, Alemanha);

- Prêmio Die Blaue Brillenschlange (Zurique, Suíça);

- Ocupa a cátedra de Poetik Dozentur na Universidade de Tubigem, Alemanha (1996).

_ Prêmio Lifetime Achievement Award, em 2006;

_ Prêmio Camões, em 2008.

Versões dos romances Sargento Getúlio, Viva o povo brasileiro e O sorriso do lagarto foram publicadas nos Estados Unidos, Alemanha, Inglaterra, França, Itália, Portugal, Espanha, Holanda, Suécia, Cuba, Hungria, Noruega, Finlândia, Dinamarca, (na antiga) União Soviética, Israel e Canadá. 


\section{EXPERIÊNCIA NA ALEMANHA}

Figura 2: Capa da edição alemã (1994), de Um brasileiro em Berlim

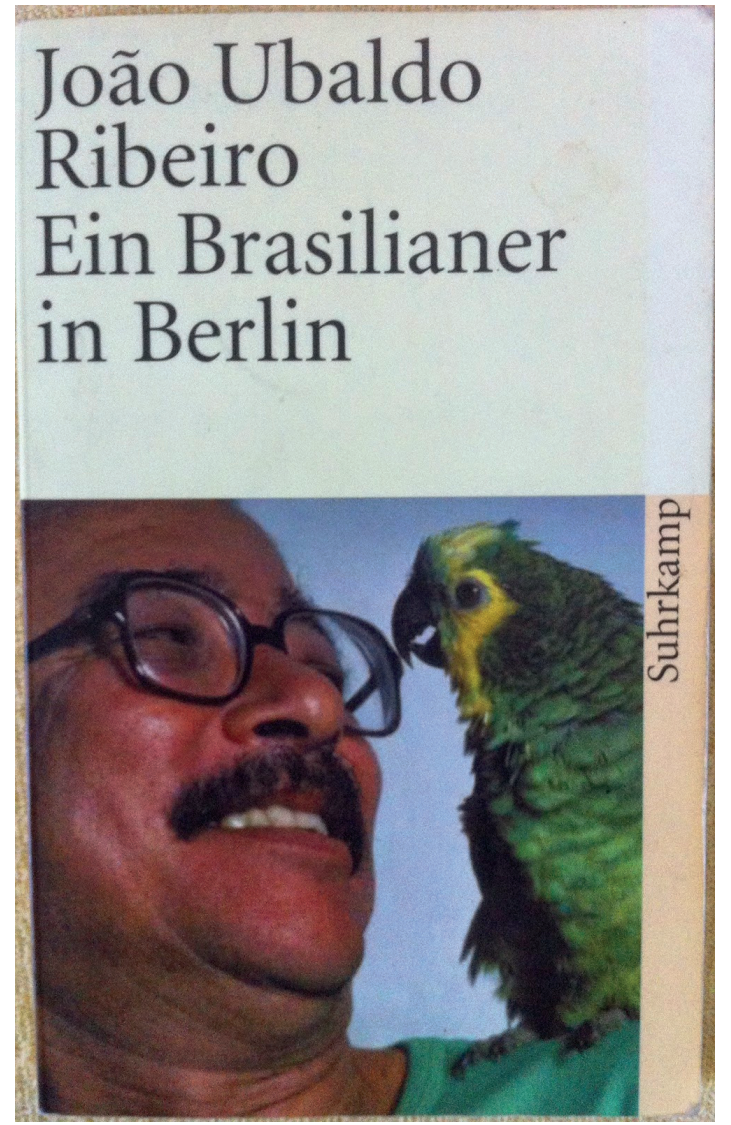

Fonte: Ein Brasilianer in Berlin. Buch von João Ubaldo Ribeiro (Suhrkamp Verlag)

Além da temática da formação do gosto pela leitura presente em "Um brasileiro em Berlim", o título se notabiliza por um olhar sobre as representações do "outro", no caso o alemão, e aquelas associadas a um novo empreendimento de delimitação dos traços distintivos do brasileiro.

Os espirituosos registros de costumes trazem consigo, além de aspectos comezinhos da paisagem urbana berlinense de final do século $X X$, em que se podem contar tipos humanos e hábitos culturais os mais variadas, também elementos férteis para a reflexão acerca das idiossincrasias que presidem a relação com o conhecimento, seu maior ou menor diálogo com as estruturas de representação do real, no modo como a figura do literato é delineada pelo autor ao se deter em traços dos perfis de escritores teutões e brasileiros (ou latino-americanos, numa acepção mais lata, um tanto provocadora e jocosa, é verdade, como na passagem em que João Ubaldo afirma, em alusão a Villa-Lobos: "o grande compositor brasileiro, ou colombiano, ou venezuelano, ou boliviano, é tudo a mesma coisa" (RIBEIRO, 2011, p. 8). Associados que também estão, nos apontamentos do autor, tais dispositivos mentais a comportamentos e práticas da rotina não intelectual, o que se confi- 
gura no pano de fundo da escrita ubaldiana são exercícios de tradução cultural em que os destinatários se misturam: o que se nota tanto nas tentativas de descrição do brasileiro para seus pares germânicos (podemos ainda cogitar em relação ao público leitor do Frankfurter Rundschau, consumidor de seus textos) quanto o inverso, uma livre, mas todavia não absolutamente errática, empresa de inteligir acerca do que singulariza o alemão. Ressalta-se, contudo, que, provavelmente não satisfeito com generalizações, venha a se divertir (consigo e provocando sensação parecida no leitor) com suposições sobre a inexistência do alemão autêntico. Essa postura aparece na crônica "Procurando o alemão", com enfiadas do tipo:

(...) fizemos diversas tentativas de conhecer um alemão, mas todas, apesar de muito esforçadas, têm invariavelmente falhado. Entre nossos amigos de Berlim, não há um só alemão. Em números aproximados: quarenta por cento se acham berlinenses e consideram os alemães um povo exótico que mora longe; trinta por cento se sentem ofendidos com a pergunta, indagam se estamos querendo insinuar alguma coisa e fazem um comício contra o nacionalismo; quinze por cento são ex-Ossies que não conseguem se acostumar a não ser mais Ossies; e os restantes quinze por cento não se sentem alemães, povo sombrio, sem graça, fechado etc. etc. (RIBEIRO, 2011, p. 32)

Os esforços de tradução cultural, ainda que emoldurados por forte dose de ironia, integram-se, ao seu modo, a uma vertente que atravessa boa parte da produção literária de João Ubaldo, a busca pelos traços mais distintivos do espírito ou, antes, do tipo brasileiro (por vezes do nordestino). Essa vertente aparece, por exemplo, de maneira bastante contundente nos romances "Sargento Getúlio" e "Viva o povo brasileiro". No livro de 1971, em que "as fontes eruditas se alternam com as populares, e a estrutura considerada comercial convive com a sofisticada intertextualidade" (ENCICLOPÉDIA Itaú Cultural de Arte e Cultura Brasileira, 2021, verbete João Ubaldo Ribeiro), percebe-se o interesse do autor em investigar "a existência de uma identidade nacional", dada a ver ao se cruzar as relações entre existências individuais e as estruturas sociais, históricas e culturais que pesam ou exercem sua força nos constrangimentos a que se veem deparados seus personagens. No romance de 1984, Ribeiro prossegue em suas incursões de uma ideia de Brasil, àquela altura ampliando ainda mais sua lente, a qual abrange quase três séculos e meio de nossa história, embora concentrada em maior parte nos 150 anos que vão desde a Independência até os ano imediatamente anteriores à sua publicação, distribuída numa narrativa que toma como eixo central a dinâmica da formação e reprodução do poderio das famílias estabelecidas na ilha de Itaparica, sua terra natal, digladiando-se pelo controle do poder local.

Em "Um brasileiro em Berlim" Ribeiro deixa entrever, no contraponto às descrições que vai enfileirando sobre os alemães, um olhar arguto sobre as representações e autorrepresentações acerca dos seus conterrâneos. Estas aparecem com toda força, por exemplo, na crônica Sexy Brasil, Sexy Berlin, em que arquétipos da brasilidade, como índios/as da 
Amazônia, a fragilidade do funcionamento das instituições políticas democráticas, personalizada pela figura de "ditadores militares cobertos de medalhas do tamanho de panquecas" (p. 11), os modelos sexualizados, tipificada pela imagem icônica de Carmen Miranda e uma sorte variada de estereótipos femininos são trazidos à baila para provocar uma autoanálise sobre os rótulos mais vulgares com que somos representados no exterior. O erotismo e as reações quanto aos padrões morais da sexualidade ganham relevância nessa quadra e são compreendidos por João Ribeiro na chave analítica em que os valores nacionais estariam mais próximos de manifestações dos elementos da natureza. Uma suposta liberalidade sexual, uma propensão natural aos "prazeres da carne", são focalizadas por uma crítica incisiva, em que nossas imagens e autoimagens cedem o passo à emergência de dispositivos de controle de nossos "eflúvios" mais insinuantes. Sexy Berlin, nome de um programa de noturno em uma emissora de televisão alemã - e que despertara o interesse de Bento, filho de João Ubaldo que contava então apenas oito anos - e os episódios assistidos na Hochmeisterplatz, também por este último, em que, de acordo com o menino, "'estava todo mundo nu!", tendo ainda “'duas moças se beijando na boca!” (p. 12), são evocados para produzir no leitor, além da fruição literária, pequenas incursões mentais sobre o horizonte de nossas sensibilidades, balizadas, no texto, pela descoberta de Bento de nova faceta da assimetria comportamental entre brasileiros e germânicos, ao constatar que em Berlim "não tem uma porção de melindres e fricotes, como no Brasil” (p. 12).

É possível afirmar que todo o livro é atravessado pelas tentativas de tradução cultural, mas em algumas das crônicas a temática é explícita. Batalhas culturais, título de outra das crônicas, capta as estratégias de aproximação cultural entabuladas quando da estada em Berlim. O enquadramento abarca, prioritariamente, os visitantes que João Ubaldo recebe em sua casa para almoçar, em especial Marc, amigo de Bento. A culinária - e a atratividade que pratos típicos exóticos podem exercer nos habitantes autóctones - então, é alçada pelo autor a protagonista dos encontros teuto-brasileiros. Trata-se de uma bem-humorada sátira das consequências alimentares provocadas nos visitantes da residência do autor. O contexto que envolve essa trama, bem se percebe, possui vinculação com o binômio matéria/espírito, já que a apresentação das "coisas" do Brasil por intermédio da gastronomia tupiniquim é acionada em paralelo a uma hipotética (na crônica o autor dá como favas contadas a superioridade da "conquista cultural" pelo estômago) disputa com a capacidade de atração dos textos literários. Nesse cenário, Marc surge como grande esperança de João Ubaldo de deixar suas marcas indeléveis em terras germânicas.

Fiquei emocionado. Marc era agora a cabeça de ponte de minha batalha cultural. Um jovem alemão exposto tão vitalmente à cultura brasileira, ali estava um futuro amigo e amante do Brasil, minha missão cultural abria um novo e fecundo horizonte. Com orgulho paternal, passei a abrir a porta para Marc nos nossos cada vez mais frequentes almoços e responder-Ihe "sim, sim, meu caro Marc", quando ele perguntava se hoje tinha faar-rô-fah. "Esse menino é um talento", dizia eu a minha 
mulher. "Precisamos dar um jeito de ele pelo menos passar umas férias no Brasil." (RIBEIRO, 2011, p. 25)

A "batalha cultural" se encerra com uma troça praticada contra si mesmo (em que se produz um efeito de generalização quanto ao potencial de sedução das obras literárias), na qual Ubaldo nos relata que a garantia de ter Marc como companhia nos almoços foi conquistada por estratagema de Bento, que chantageou a mãe de seu amigo a deixar que o visitassem sob a ameaça de que, caso contrário, seria obrigada a ler livros de Ubaldo.

\section{EXPERIÊNCIA COM O GOSTO PELA LEITURA}

Figura 2: Capa da edição alemã (1994), de Um brasileiro em Berlim.

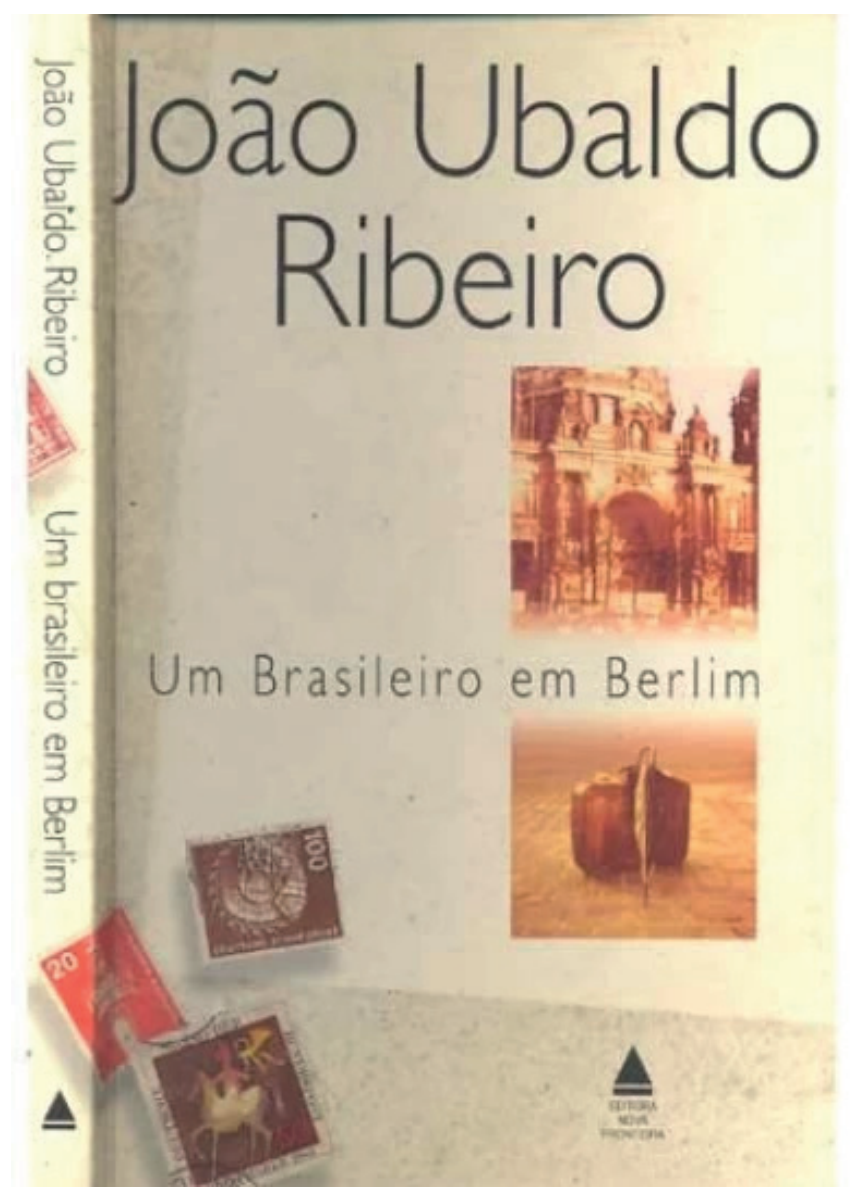

Fonte: Um Brasileiro em Berlim - João Ubaldo Ribiro - 852090694 (megaleitores.com.br)

Nada, porém, era como os livros. Toda a família sempre foi obsedada por livros e às vezes ainda arma brigas ferozes por causa de livros, entre acusações mútuas de furto ou apropriação indébita. Meu avô furtava livros de meu pai, meu pai furtava livros de meu avô, eu furtava livros de meu pai e minha irmã até hoje furta livros de todos nós. A maior casa onde moramos, mais ou menos a partir da época em que aprendi a ler, tinha uma sala reservada para a biblioteca e gabinete de meu pai, mas os livros não cabiam nela — na verdade, mal cabiam na casa. E, embora os interes- 
ses básicos dele fossem Direito e História, os livros eram sobre todos os assuntos e de todos os tipos. (p. 105)

Assim Ubaldo descreve o ambiente no qual cresceu, o gosto da família pela leitura instigou o futuro escritor, ainda menino, a conhecer os livros.

A forma como é iniciada a nossa relação com a leitura e com os livros enquanto objetos ocorre de múltiplas formas: no ambiente familiar, no ambiente escolar, nas enciclopédias, das coleções de histórias infantis ao livro brinquedo, ao livro de banho, ao livro de pano, ao livro de montar, ao e-book. Se o livro enquanto objeto mudou com o passar do tempo, a nossa relação com ele também tem sido transformada. O início da nossa relação com os livros pode marcar o desenvolvimento do gosto pela leitura e a constituição do hábito de ler, entendendo o mesmo como a criação da necessidade de realizar tal atividade para a obtenção de algum tipo de satisfação, como buscar conhecimento, ocupar o tempo livre ou simplesmente para sentir prazer. O pai de Ubaldo, o jurista Manuel Ribeiro, foi um ávido leitor e admirador dos clássicos, que apresentou os livros ao filho desde cedo. No texto "Memória de livros", sua impaciência para que o menino logo começasse a ler é evidenciada com ternura:

Não sei bem dizer como aprendi a ler. A circulação entre os livros era livre (tinha que ser, pensando bem, porque eles estavam pela casa toda, inclusive na cozinha e no banheiro), de maneira que eu convivia com eles todas as horas do dia, a ponto de passar tempos enormes com um deles aberto no colo, fingindo que estava lendo e, na verdade, se não me trai a vã memória, de certa forma lendo, porque quando havia figuras, eu inventava as histórias que elas ilustravam e, ao olhar para as letras, tinha a sensação de que entendia nelas o que inventara. Segundo a crônica familiar, meu pai interpretava aquilo como uma grande sede de saber cruelmente insatisfeita e queria que eu aprendesse a ler já aos quatro anos, sendo demovido a muito custo, por uma pedagoga amiga nossa. Mas, depois que completei seis anos, ele não aguentou, fez um discurso dizendo que eu já conhecia todas as letras e agora era só uma questão de as juntar e, além de tudo, ele não suportava mais ter um filho analfabeto. Em seguida, mandou que eu vestisse uma roupa de sair, foi comigo a uma livraria, comprou uma cartilha, uma tabuada e um caderno e me levou à casa de D. Gilete. (p. 106-107)

Dona Gilete era uma professora que ensinava em casa. Quando a apresentou, seu pai disse:

(...) este rapaz já está um homem e ainda não sabe ler. Aplique as regras: "Aplicar as regras", soube eu muito depois, com um susto retardado, significava, entre outras coisas, usar a palmatória para vencer qualquer manifestação de falta de empenho ou burrice por parte do aluno. Felizmente D. Gilete nunca precisou me aplicar as regras, mesmo porque eu de fato já conhecia a maior parte das letras e juntá-las me pareceu facílimo, de maneira que, quando voltei para casa nesse mesmo dia, já estava começando a poder ler. Fui a uma das estantes do corredor para selecionar um daqueles livrões com retratos de homens carrancudos e cenas de batalhas, mas 
meu pai apareceu subitamente à porta do gabinete, carregando uma pilha de mais de vinte livros infantis. (p. 107)

Tão logo foi alfabetizado, seu pai se encarregou de dar-lhe muitos livros, com o intuito que durassem alguns dias:

Duraram bem pouco, sim, porque de repente o mundo mudou e aquelas paredes cobertas de livros começaram a se tornar vivas, frequentadas por um número estonteante de maravilhas, escritas de todos os jeitos e capazes de me transportar a todos os cantos do mundo e a todos os tipos de vida possíveis. Um pouco febril às vezes, chegava a ler dois ou três livros num só dia, sem querer dormir e sem querer comer porque não me deixavam ler à mesa - e, pela primeira vez em muitas, minha mãe disse a meu pai que eu estava maluco, preocupação que até hoje volta e meia ela manifesta. (p. 107)

A mãe justificou a preocupação ao ver o filho cheirando livros e lendo dicionários, hábitos que não causaram estranhamento ao seu pai, que fazia o mesmo.

Ubaldo conversava muito com o pai sobre os livros e este, para instigá-lo a conhecer títulos variados, dividia a leitura entre compulsória e livre, e esta entre "livre propriamente dita" e "incerta". Este trecho do livro, apesar de extenso, vale a pena ser transcrito na íntegra:

A compulsória variava conforme a disposição de meu pai. Havia a leitura em voz alta de poemas, trechos de peças de teatro e discursos clássicos, em que nossa dicção e entonação eram invariavelmente descritas como o pior desgosto que ele tinha na vida. Líamos Homero, Camões, Horácio, Jorge de Lima, Sófocles, Shakespeare, Euclides da Cunha, dezenas de outros. Muitas vezes não entendíamos nada do que líamos, mas gostávamos daquelas palavras sonoras, daqueles conflitos estranhos entre gente de nomes exóticos, e da expressão comovida de minha mãe, com pena de Antígona e torcendo por Heitor na llíada. Depois de cada leitura, meu pai fazia sua palestra de rotina sobre nossa ignorância e, andando para cima e para baixo de pijama na varanda, dava uma aula grandiloquente sobre o assunto da leitura, ou sobre o autor do texto, aula esta a que os vizinhos muitas vezes vinham assistir. Também tínhamos os resumos - escritos ou orais - das leituras, as cópias (começadas quando ele, com grande escândalo, descobriu que eu não entendia direito o ponto e vírgula e me obrigou a copiar sermões do Padre Antônio Vieira, para aprender a usar o ponto e vírgula) e os trechos a decorar. No que certamente é um mistério para os psicanalistas, até hoje não só os sermões de Vieira como muitos desses autores forçados pela goela abaixo estão entre minhas leituras favoritas. (Em compensação, continuo ruim de ponto e vírgula.) Mas o bom mesmo era a leitura livre, inclusive porque oferecia seus perigos. Meu pai usava uma técnica maquiavélica para me convencer a me interessar por certas leituras. A circulação entre os livros permanecia absolutamente livre, mas, de vez em quando, ele brandia um volume no ar e anunciava com veemência:

— Este não pode! Este está proibido! Arranco as orelhas do primeiro que chegar perto deste daqui! 
O problema era que não só ele deixava o livro proibido bem à vista, no mesmo lugar de onde o tirara subitamente, como às vezes a proibição era para valer. A incerteza era inevitável e então tínhamos momentos de suspense arrasador (meu pai nunca arrancou as orelhas de ninguém, mas todo mundo achava que, se fosse por uma questão de princípios, ele arrancaria), nos quais lemos Nossa vida sexual do Dr. Fritz Kahn, Romeu e Julieta, O livro de San Michele, Crônica escandalosa dos Doze Césares, Salambô, O crime do Padre Amaro - enfim, dezenas de títulos de uma coleção estapafúrdia, cujo único ponto em comum era o medo de passarmos o resto da vida sem orelhas - e hoje penso que li tudo o que ele queria disfarçadamente que eu lesse, embora à custa de sobressaltos e suores frios." (p. 108-109)

Na orelha do livro "Um brasileiro em Berlim", Jorge Amado afirma que "se João Ubaldo é hoje um dos principais escritores do Brasil - e da literatura contemporânea -, creio que ele o deve, sobretudo, ao pai que, tentando aparentemente contê-lo, lhe deu régua e compasso."

A relação com os avós paternos também foi muito importante para a formação do leitor Ubaldo. João, o avô, não levava o filho muito a sério intelectualmente porque dizia que as monografias jurídicas que ele escrevia eram muito finas e não se sustentavam em pé. A avó, Amália, respeitava a produção do filho, mas acreditava que havia estudado muito as "altas ciências" e "não entendia nada da vida". Assim, ela oferecia a Ubaldo tudo aquilo que acreditava que o pai não ofereceria como, por exemplo, revistas policiais proibidas para menores de idade. Nas férias escolares, a avó o buscava, deixando seu pai preocupado:

- D. Amália - dizia ele, tratando-a com cerimônia na esperança de que ela se imbuísse da necessidade de atendê-lo —, o menino vai com a senhora, mas sob uma condição. A senhora não vai deixar que ele fique o dia inteiro deitado, cercado de bolachinhas e docinhos e lendo essas coisas que a senhora lê.

— Senhor doutor — respondia minha avó —, sou avó deste menino e tua mãe. Se te criei mal, Deus me perdoe, foi a inexperiência da juventude. Mas este cá ainda pode ser salvo e não vou deixar que tuas maluquices o infelicitem. Levo o menino sem condição nenhuma e, se insistes, digo-te muito bem o que podes fazer com tuas condições e vê lá se não me respondes, que hoje acordei com a ciática e não vejo a hora de deitar a sombrinha ao lombo de um que se atreva a chatear-me. Passar bem, Senhor doutor. E assim eu ia para a casa de minha avó Amália, onde ela comentava mais uma vez com meu avô como o filho estudara demais e ficara abestalhado para a vida, e meu avô, que queria que ela saísse para poder beber em paz a cerveja que o médico proibira, tirava um bolo de dinheiro do bolso e nos mandava comprar umas coisitas de ler - Amália tinha razão, se o menino queria ler, que lesse, não havia mal nas leituras, havia em certos leitores. (p. 110)

E então, em férias com a avó, os dois iam à maior banca de revistas da cidade e à livraria e compravam tantas revistas e romances policiais que não podiam sequer carregar e mandavam entregar em casa. 
"De volta à casa de meus pais, depois das férias, o problema das leituras compulsórias às vezes se agravava, porque meu pai, na certeza (embora nunca desse ousadia de me perguntar) de que minha avó me tinha dado para ler tudo o que ele proibia, entrava numa programação delirante, destinada a limpar os efeitos deletérios das revistas policiais. Sei que parece mentira e não me aborreço com quem não acreditar (quem conheceu meu pai acredita), mas a verdade é que, aos doze anos, eu já tinha lido, com efeitos às vezes surpreendentes, a maior parte da obra traduzida de Shakespeare, O elogio da loucura, As décadas de Tito Lívio, D. Quixote (uma das ilustrações de Gustave Doré, mostrando monstros e personagens saindo dos livros de cavalaria do fidalgo, me fez mal, porque eu passei a ver as mesmas coisas saindo dos livros da casa), adaptações especiais do Fausto e da Divina comédia, a llíada, a Odisseia, vários ensaios de Montaigne, Poe, Alexandre Herculano, José de Alencar, Machado de Assis, Monteiro Lobato, Dickens, Dostoievski, Suetônio, os Exercícios espirituais de Santo Inácio de Loyola e mais não sei quantos outros clássicos, muitos deles resumidos, discutidos ou simplesmente lembrados em conversas inflamadas, dos quais nunca me esqueço e a maior parte dos quais faz parte íntima de minha vida." (p. 111-112)

Os clássicos, livros que superam o tempo, e tem papel estruturante na formação do leitor. Lembrando as palavras de Ítalo Calvino (1993), os efeitos educativos destes livros

(...) dão uma forma às experiências futuras, fornecendo modelos, recipientes, termos de comparação, esquemas de classificação, escalas de valores, paradigmas de beleza: todas coisas que continuam a valer mesmo que nos recordemos pouco ou nada do livro lido (...) Existe uma força particular da obra que consegue fazer-se esquecer enquanto tal, mas que deixa sua semente... (p. 10)

O conhecimento dos clássicos aliado ao conhecimento da cultura regional proliferaram nos livros do autor Ubaldo, que fez uso palavras que integraram o dialeto denominado por ele como "sergipês", que tanto marcaram a sua obra. De acordo com Maria Alice Antunes (2007): "o 'sergipês', causador de dificuldades de compreensão para tradutores e leitores, estrangeiros ou não, não apresentou desafios para o autotradutor, conhecedor do dialeto, e o ato cooperativo da leitura foi facilitado pelo fato de que o autor, a quem são atribuídas as escolhas lexicais e sintáticas, por exemplo, registradas no nível da manifestação linear do texto, foi também o tradutor. Não quero dizer com isto que João Ubaldo tenha sido o "melhor" tradutor ou o "único" capaz de construir uma interpretação coerente. Ressalto apenas que sua competência enciclopédica, que abrange a subcompetência bilíngue e, portanto, o conhecimento do "sergipês", deu a ele uma vantagem sobre o tradutor que iniciou a tarefa." (p. 175)

\section{O CAPITAL CULTURAL E A FORMAÇÃO DO LEITOR/ESCRITOR}

O conceito de capital cultural foi formulado pelo sociólogo Pierre Bourdieu, no contexto da sociedade francesa de meados dos anos 1960, como uma ferramenta conceitual que pudesse explicar as desigualdades de rendimento escolar verificadas entre os alunos, deslocando a expli- 
cação dos fatores de ordem individual, como a suposta inteligência, a aptidão ou o "dom", para os fatores de ordem social, em particular, o meio sociocultural de pertencimento da criança. Bourdieu (1998) afirma que "cada família transmite a seus filhos, mais por vias indiretas que diretas, um certo capital cultural e um certo ethos, sistema de valores implícitos e profundamente interiorizados, que contribui para definir, entre outras coisas, as atitudes em face do capital cultural e da instituição escolar" (Bourdieu, 1998, p. 42). Ou seja, a posse de determinado capital cultural e de um ethos familiar predisposto a incentivar e a valorizar o conhecimento escolar seriam importantes elementos para se chegar ao sucesso acadêmico. Assim, as crianças com maior acesso aos bens culturais seriam aquelas que teriam as maiores chances de obter um bom desempenho escolar. Bourdieu alertou para as diferenças nas condições de acesso a uma cultura geral e, como decorrência, apontou para as condições diferenciadas de aquisição de uma cultura escolar. Desta forma, distinguiu duas formas de aprendizado; de um lado, o aprendizado precoce, efetuado desde a primeira infância, no ambiente familiar, podendo ou não ser prolongado por um aprendizado escolar que o complementa; de outro, o aprendizado tardio, adquirido fora da família, nas instituições de ensino ou em outras esferas informais da educação. A distinção entre esses dois tipos de aprendizado refere-se, pois, a duas maneiras de adquirir a cultura e de ter acesso a ela, e com ela se familiarizar (Bourdieu, 1998). Em artigo publicado nos anos de 1960, baseando-se em dados oriundos da demografia francesa da época, ele afirmava o papel central desempenhado pela distribuição desigual dos bens culturais entre as classes sociais para as diferenças de rendimento escolar: "com renda igual, a proporção de bons alunos varia de maneira significativa segundo o pai não seja diplomado ou seja bacharel, o que permite concluir que a ação do meio familiar sobre o êxito escolar é quase exclusivamente cultural” (BOURDIEU, 1998, p. 42).

Para o autor, o "capital cultural" é um conceito que explicita um novo tipo de capital, um novo recurso social, fonte de distinção e poder em sociedades em que a posse desse recurso é privilégio de poucos (Bourdieu, 1996). Refere-se a um conjunto de estratégias, valores e disposições promovidos principalmente pela família, pela escola e pelos demais agentes da educação, que predispõe os indivíduos a uma atitude de reconhecimento ante as práticas educativas. Em Os três estados do capital cultural Bourdieu (1998) explicita e constrói uma definição para as três modalidades deste conceito: capital cultural incorporado, capital cultural objetivado e capital cultural institucionalizado - capital cultural incorporado, sob a forma de disposições duráveis do organismo; capital cultural objetivado, sob a forma de bens culturais materiais; e o capital cultural institucionalizado, sob a forma de diplomas e titulação. Referindo-se à experiência cultural da classe média e da elite, e baseados sobretudo em uma cultura familiar e escolar distintiva. Para ele, as diferenças de acesso à cultura e de aquisição desta entre os diferentes grupos sociais conferem aos mais privilegiados um poder simbólico e real que os favorece a apresentar os melhores desempenhos escolares.

A respeito da importância da leitura e da escrita na aquisição capital cultural de acordo com as pesquisas de Bourdieu e Passeron, Maria Alice Nogueira e Débora Piotto (2021) ponderam: 
No bojo dessa discussão, os autores levantam uma questão que consideramos de especial importância para a pesquisa educacional brasileira: o papel da leitura/ escrita no sucesso escolar. Ao abordar a questão da eficácia e da transmissibilidade do capital cultural familiar, e com base em um conjunto de pesquisas, eles afirmam que se a alta cultura não ocupa mais o lugar de outrora nos currículos, a socialização escolar, por sua vez, nunca deixou de passar pela escrita e, por isso, a leitura continua a desempenhar papel fundamental no sucesso acadêmico. E eles concluem: mais do que a familiaridade com a cultura legítima, são as práticas de leitura dos estudantes que se revelam escolarmente eficazes na medida em que elas produzem efeitos linguísticos e cognitivos (p. 4).

No livro Os herdeiros: os estudantes e a cultura, Pierre Bourdieu e Jean-Claude Passeron colocam em questão a ideia de igualdade de oportunidades de acesso à universidade, esmiúçam, mediante dados empíricos, os sentidos da democratização da educação a partir de um momento no qual o sistema demonstra oferecer as mesmas oportunidades a todos. Ao fazê-lo, a obra evidencia a relação entre a classe dominante, o seu capital cultural e o modo de funcionamento do ensino superior e os modos pelos quais alguns estudantes detém vantagens sobre os outros. Publicado em 1964, o trabalho teve grande repercussão no meio acadêmico e nos movimentos sociais. O termo "herdeiro" foi incorporado no livro para referir-se aos filhos das famílias cultas que serão orientados para os cursos de ensino superior mais valorizados socialmente. As análises realizadas evidenciam que a função de perpetuação das desigualdades diante da cultura é predominante nos processos de escolarização, mediante práticas pedagógicas, de ensino e de avaliação, os privilégios sociais são convertidos em méritos, talentos individuais e dons: "para uns, a aprendizagem da cultura da elite é uma conquista que se paga caro; para outros, uma herança que compreende ao mesmo tempo a facilidade e as tentações da facilidade" (BOURDIEU e PASSERON, 2014, p. 9). Dotados de um "corpo de saberes, de saber-fazer e de saber-dizer que constitui o patrimônio das classes cultas" (op. cit., p. 10), tais estudantes têm sua relação com a universidade favorecida por trata-se da mobilização de uma herança, enquanto os filhos das classes desfavorecidas ao ingressarem no sistema de ensino e entrarem em contato com a cultura escolar, precisam adaptar-se a tal cultura por estarem muito longe da lógica da vida universitária. Na vida de Ubaldo, a cultura letrada sempre foi extremamente importante e valorizada. Se o livro é a chave da alfabetização formal, o menino circulava entre estes volumes antes mesmo de aprender a ler e escrever.

\section{CONSIDERAÇÕES FINAIS}

Herdeiro de uma família abastada, conforme menciona em suas memórias:

(...) mas vivíamos bem. Morávamos sempre em casarões enormes, de grandes portas, varandas e tetos altíssimos, e meu pai, que sempre gostou das últimas novidades tecnológicas, trazia para casa tudo quanto era tipo de geringonça moderna que aparecia. Fomos a primeira família da vizinhança a ter uma geladeira e recebemos 
visitas para examinar o impressionante armário branco que esfriava tudo. Quando surgiram os primeiros discos long play, já tínhamos a vitrola apropriada e meu pai comprava montanhas de gravações dos clássicos, que ele próprio se recusava a ouvir, mas nos obrigava a escutar e comentar. (p. 105).

Aliado ao capital econômico, que lhe favoreceu o acesso a bens de consumo e a práticas culturais variadas desde a infância, o ambiente familiar e a relação com o pai, jurista, que havia cursado o ensino superior no início do século XX - o que no Brasil neste período era algo bastante raro e reservado a poucos - e com os seus avós propiciou-Ihe o capital cultural necessário para fazer das práticas de leitura mais do que um hábito, criaram uma necessidade, algo que se busca constantemente para realizar algum tipo de satisfação. Enveredando pelas ciências humanas, Ubaldo tornou-se escritor, professor, jornalista, ofícios que dependem constantemente da leitura e da escrita. De ávido leitor passou a exercer a escrita com maestria, tornando-se então um dos principais escritores da literatura brasileira do século XX. Bourdieu nos ajuda a compreender o papel que o capital cultural tem nas trajetórias de sucesso acadêmico, a história de Ubaldo nos ajuda a reiterar esta perspectiva. Ao recordar sua infância cercado de livros, revistas e tertúlias literárias com a família, afirma:

(...) fico pensando nisso e me pergunto: não estou imaginando coisas, tudo isso poderia ter realmente acontecido? Terei tido uma infância normal? Acho que sim, também joguei bola, tomei banho nu no rio, subi em árvores e acreditei em Papai Noel. Os livros eram uma brincadeira como outra qualquer, embora certamente a melhor de todas. Quando tenho saudades da infância, as saudades são daquele universo que nunca volta, dos meus olhos de criança vendo tanto que entonteciam, dos cheiros dos livros velhos, da navegação infinita pela palavra, de meu pai, de meus avós, do velho casarão mágico de Aracaju. (p. 112)

Conhecer o potencial formativo da relação com a leitura e suas práticas a partir de relatos memorialísticos evidencia-se como um terreno fértil no qual o conhecimento acerca da educação com a literatura pode proliferar. 


\section{REFERÊNCIAS BIBLIOGRÁFICAS}

ANTUNES, M. A. G. O RESPEITO PELO ORIGINAL Uma análise da autotradução a partir do caso de João Ubaldo Ribeiro. Tese de Doutorado. Programa de Pós-graduação da PUC-Rio, 2007.

BENJAMIN, W. A tarefa do tradutor. Trad. Karlheinz Barck et al. Revisão de Johannes Kretschmer. Cadernos de Mestrado/Literatura. Rio de Janeiro: UERJ/Instituto de Letras, 1994.

BERND, Z. O caminho do meio: uma leitura da obra de João Ubaldo Ribeiro. Porto Alegre: Ed. UFRGS, 2001.

BOURDIEU, P.; PASSERON, J.C. Escritos de educação . Petrópolis: Vozes, 1998.

BOURDIEU, P.; PASSERON, J.C. Os herdeiros: os estudantes e a cultura. Florianópolis: Ed. da UFSC, 2014.

BOURDIEU, P.; PASSERON, J.C. Razões práticas: sobre a teoria da ação. Campinas: Papirus, 1996.

BUENO, E. "AAlemanha sob o crivo e riso de um cronista pícaro" e "A aventura berlinense de João Ubaldo Ribeiro". O Estado de S. Paulo, 13/10/90.

CALVINO, I. Por que ler os clássicos? (5a ed.). São Paulo: Companhia das Letras, 1993.

CANCLINI, N. R. G. Culturas híbridas. Estratégias para entrar y salir de la modernidad. Buenos Aires: Paidós, 2001.

COUTINHO, W. João Ubaldo Ribeiro: um estilo de sedução. Rio de Janeiro: Relume Dumará/Prefeitura Municipal do Rio de Janeiro/RioArte, 1998. (Coleção "Perfis do Rio")

João Ubaldo Ribeiro. In: Acadêmicos da Academia Brasileira de Letras. Disponível em: João Ubaldo Ribeiro |Academia Brasileira de Letras. Acesso em: 12 de dezembro de 2021.

João Ubaldo Ribeiro. In: ENCICLOPÉDIA Itaú Cultural de Arte e Cultura Brasileira. São Paulo: Itaú Cultural, 2021. Disponível em: http://enciclopedia.itaucultural.org.br/pessoa7658/joao-ubaldo-ribeiro. Acesso em: 11 de dezembro de 2021.

NOGUEIRA, M. A.; PIOTTO, D. Um balanço do conceito de capital cultural: contribuições para a pesquisa em educação. Revista Educação e Pesquisa, São Paulo, v. 47, e470100302, 2021.

OLIVIERI-GODET, R. Construções identitárias na obra de João Ubaldo Ribeiro. São Paulo: Hucitec; Feira de Santana (BA): Ed. UEFS; Rio de Janeiro: Academia Brasileira de Letras, 2009.

RIBEIRO, J. U. Um brasileiro em Berlim. Rio de Janeiro: Ed. Objetiva, 2011.

SILVERMAN, M. As distintas facetas de João Ubaldo Ribeiro. In: Moderna ficção brasileira, vol. 2. Trad. João Guilherme Linke. Rio de Janeiro: Civilização Brasileira / Brasília: Instituto Nacional do Livro, 1981, p. 89-109. 